\title{
Clinical significance of the nuclear receptor co-regulator DC-SCRIPT in breast cancer: an independent retrospective validation study
}

\author{
Anieta M Sieuwerts ${ }^{1 \dagger}$, Marleen Ansems ${ }^{2 \dagger}$, Maxime P Look', Paul N Span ${ }^{3}$, Vanja de Weerd ${ }^{1}$, Anne van Galen',
} John A Foekens ${ }^{1}$, Gosse J Adema ${ }^{2 *}$, John WM Martens ${ }^{1}$

\begin{abstract}
Introduction: In this study we aimed to validate the prognostic value of DC-SCRIPT mRNA expression in a large independent breast cancer cohort. In addition, since DC-SCRIPT is a transcriptional co-regulator of nuclear receptors, we explored its prognostic value in relation to estrogen-receptor- $\alpha$ (ESR1) and $-\beta$ (ESR2) and evaluated its predictive value for response to tamoxifen treatment.

Methods: DC-SCRIPT mRNA levels were measured by real-time PCR in 1,505 primary invasive breast cancers and associated with outcome (disease-free survival (DFS), metastasis-free survival (MFS) and overall survival (OS)) using univariate and multivariable Cox regression analysis. Logistic and Cox regressions were used to associate DC-SCRIPT levels with clinical benefit and progression-free survival (PFS) for 296 patients treated with first-line systemic tamoxifen for advanced disease.

Results: In univariate and multivariable analysis higher DC-SCRIPT levels were associated with a favorable outcome for both the entire cohort and patients with lymph node-negative (LNN) disease that did not receive adjuvant therapy (DFS, MFS and OS; all, P < 0.001). This association was most pronounced in small (pT1) tumors, in ESR1positive tumors and in tumors with low ESR2 expression. For first-line endocrine therapy for advanced disease no predictive association was seen with clinical benefit or PFS.

Conclusions: This study provides a higher level of evidence that DC-SCRIPT is indeed an independent, pure prognostic, factor for primary breast cancer and shows that DC-SCRIPT mRNA expression is most informative for either ESR1-positive and/or ESR2-low pT1 tumors.
\end{abstract}

\section{Introduction}

Estrogens influence the aggressiveness of breast cancer through their cognate nuclear receptors. In particular, the estrogen receptor-alpha $(E R \alpha)(E S R 1)$ - present in tumor cells of about $70 \%$ to $75 \%$ of all breast tumors is considered crucial because of its proliferationinducing actions and for that reason is an important target for therapy. Next to ESR1, a second ER exists, $\operatorname{ER} \beta$ (ESR2). ESR2 counteracts the activity of ESR1 in many systems $[1,2]$ and is also expressed in the majority

\footnotetext{
* Correspondence: g.adema@ncmls.ru.nl

† Contributed equally

2Department of Tumor Immunology, Nijmegen Centre for Molecular Life Sciences, Radboud University Nijmegen Medical Centre, Geert Grooteplein 28, Nijmegen, 6525 GA, The Netherlands

Full list of author information is available at the end of the article
}

of breast cancers. Apart from breast epithelial tumor cells, ESR2 is also expressed in adjacent infiltrating lymphocytes, fibroblasts, and endothelial cells, all of which are known to influence tumor growth [3]. However, its precise role in breast cancer progression is less well defined.

DC-SCRIPT (zinc finger protein 366 [ZNF366]) is a recently identified nuclear receptor co-regulator first identified in immune cells [4-6]. Nuclear receptor coregulators are proteins that can activate or repress the transcriptional activity of nuclear receptors. DC-SCRIPT is in this respect a unique co-regulator as we have shown that it enhances the activities of the nuclear retinoic acid receptor (RAR) and peroxisome proliferatoractivated receptor (PPAR) heterodimers, RAR $\alpha / R X R \alpha$ 
and PPAR $\gamma / \mathrm{RXR} \alpha$, but represses the activities of ESR1 and progesterone receptor (PGR) [7]. We also showed that DC-SCRIPT was an independent prognostic factor, particularly for hormone receptor-positive breast cancer. This led us to postulate that the anti-proliferative effect of DC-SCRIPT in breast cancer cells could be mediated by simultaneous modulation of the activity of multiple nuclear receptors.

To provide a higher level of evidence for DC-SCRIPT mRNA expression as a prognostic marker, we now report on DC-SCRIPT expression and its significance in a retrospective validation study of 1,505 breast cancer patients with known ESR1, ESR2, and PGR expression levels. The primary objective of this study was to confirm the relationship between DC-SCRIPT mRNA levels measured in primary breast cancers and tumor aggressiveness in a much larger, independent, breast cancer cohort. The main clinical endpoints for assessing the prognostic value of DC-SCRIPT expression were disease-free survival (DFS), metastasis-free survival (MFS), and overall survival (OS) in lymph node-negative (LNN) patients who had not received adjuvant systemic therapy; this approach allowed us to determine tumor aggressiveness during the natural course of the disease. As DC-SCRIPT modulates ER activity, we also analyzed the prognostic value of DC-SCRIPT separately in tumors stratified by ESR1 and ESR2 expression. Since several co-regulators of nuclear receptors also modulate response to therapy $[8,9]$, we also assessed, as a secondary aim of this study, the predictive value of DC-SCRIPT by using clinical benefit and progression-free survival (PFS) after first-line tamoxifen for advanced disease as the main endpoints.

\section{Materials and methods Patients}

The protocol to study biological markers associated with disease outcome was approved by the medical ethics committee of the Erasmus Medical Center (Rotterdam, The Netherlands) (MEC 02.953). This retrospective study used 1,505 M0 (no metastasis) and $32 \mathrm{M} 1$ (with metastasis) blind-coded freshly frozen primary tumor tissues of female patients with primary operable breast cancer from 1978 through 2000. The study was performed in accordance with the Code of Conduct of the Federation of Medical Scientific Societies in The Netherlands [10], and consent was not required. Wherever possible, the study has been reported in accordance with the Reporting Recommendations for Tumor Marker Prognostic Studies guidelines [11]. The primary breast tumors were from patients with detailed clinical follow-up as previously described [12-14]. ER protein status was determined by routine ligand-binding assays or enzyme immunoassays [15], and ESR1, ESR2, and PGR mRNA status was determined by real-time reverse transcriptase-polymerase chain reaction (RT-PCR) $[14,16,17]$. Follow-up, tumor staging, and response to therapy were defined by standard International Union Against Cancer (Geneva, Switzerland) classification criteria [18] and applied previously by Foekens and colleagues [19]. All 1,537 patients underwent breast-conserving lumpectomy (44\%) or modified mastectomy (56\%). Of the 1,505 patients included for the evaluation of tumor aggressiveness, 462 lymph node-positive patients (31\%) were treated with adjuvant systemic therapy, 207 patients received hormonal therapy, 233 chemotherapy, and 22 combination therapy. Disease recurrence occurred in 836 patients, and 703 developed a distant metastasis. The median follow-up time of patients alive was 90 months (range of 4 to 260 months).

Eight hundred thirty-seven patients had no involved nodes and did not receive systemic adjuvant therapy. Of these 837 LNN patients, 383 had a disease relapse, 300 developed a distant metastasis, and 273 died during follow-up.

Of the 703 patients who developed a distant metastasis, 296 ER-positive patients, including the $32 \mathrm{M} 1$ patients, received hormonal therapy as first-line therapy for advanced disease. Clinical benefit of first-line tamoxifen treatment was observed in 185 patients. Median follow-up time for treatment of advanced disease was 38 (4 to 120) months. Two hundred nineteen patients had died at the end of the follow-up. None of these patients had received prior adjuvant hormonal therapy, whereas $19 \%$ received prior adjuvant chemotherapy. A more detailed description of the patients and their therapy is given in the Supplementary materials and methods (Additional file 1). Patient and tumor characteristics combined with DC-SCRIPT mRNA expression and clinical outcome are listed in Table 1.

\section{RNA isolation and quantitative RT-PCR}

Tissue processing, RNA isolation, cDNA synthesis, and quantitative RT-PCR were performed as previously described [16]. Real-time quantitative PCRs were performed in a $25-\mu \mathrm{L}$ reaction volume in an $\mathrm{M} \times 3000 \mathrm{P}^{\mathrm{m}}$ Real-Time PCR System (Agilent, Amsterdam, The Netherlands). In addition to an SYBR-based assay to detect a 129-base pair (bp) DC-SCRIPT transcript covering exon 4 to 5 (forward primer: 5'-AAAGTCAAGCATGGAGTCATG-3'; reverse primer: 5'-GCTTCTGAGAGAGGTCAAAG-3'), a commercially available Taqman Gene Expression Assay from Applied Biosystems (Nieuwerkerk aan den IJssel, The Netherlands) covering exon 3 to 4 and generating a 62 -bp product was used (Hs00403536_m1, RefSeq NM_152625.1). DC-SCRIPT levels were readily detected with both assays, and data generated with these assays correlated significantly 
Table 1 Associations of DC-SCRIPT with clinicopathological and biological factors

\begin{tabular}{|c|c|c|c|c|}
\hline \multirow{2}{*}{$\frac{\text { Characteristic }}{\text { All patients }}$} & \multirow{2}{*}{$\frac{\text { Number of patients }}{1,505}$} & \multirow{2}{*}{$\begin{array}{c}\text { Percentage }^{\mathrm{a}} \\
100 \%\end{array}$} & \multicolumn{2}{|c|}{$D C$-SCRIPT ${ }^{\mathrm{b}}$ (reference-normalized),$\times 10^{2}$} \\
\hline & & & 0.69 & 0.73 \\
\hline \multicolumn{5}{|l|}{ Age, years } \\
\hline$\leq 40$ & 192 & $13 \%$ & 0.69 & 0.72 \\
\hline $41-55$ & 561 & $37 \%$ & 0.70 & 0.74 \\
\hline $56-70$ & 498 & $33 \%$ & 0.70 & 0.77 \\
\hline \multirow[t]{2}{*}{$>70$} & 254 & $17 \%$ & 0.64 & 0.64 \\
\hline & & & $P=0.15^{c}$ & \\
\hline \multicolumn{5}{|l|}{ Menopausal status } \\
\hline Premenopausal & 637 & $42 \%$ & 0.72 & 0.74 \\
\hline \multirow[t]{2}{*}{ Postmenopausal } & 868 & $58 \%$ & 0.66 & 0.70 \\
\hline & & & $P=0.06^{\mathrm{d}}$ & \\
\hline \multicolumn{5}{|l|}{ Grade } \\
\hline Poor & 818 & $54 \%$ & 0.64 & 0.74 \\
\hline Unknown & 452 & $30 \%$ & 0.71 & 0.68 \\
\hline \multirow[t]{2}{*}{ Moderate and good } & 235 & $16 \%$ & 0.80 & 0.70 \\
\hline & & & $P=0.001$ & \\
\hline \multicolumn{5}{|l|}{ Tumor size } \\
\hline $\mathrm{pT} 1, \leq 2 \mathrm{~cm}$ & 517 & $34 \%$ & 0.81 & 0.84 \\
\hline \multirow{2}{*}{$>2 \mathrm{~cm}$} & 988 & $66 \%$ & 0.63 & 0.64 \\
\hline & & & $P<0.001$ & \\
\hline \multicolumn{5}{|l|}{ Lymph nodes involved } \\
\hline No & 837 & $56 \%$ & 0.69 & 0.73 \\
\hline \multirow[t]{2}{*}{ Yes } & 668 & $44 \%$ & 0.68 & 0.75 \\
\hline & & & $P=0.64^{c}$ & \\
\hline \multicolumn{5}{|l|}{ ESR1 mRNA status ${ }^{f}$} \\
\hline Positive, $\geq 0.2$ & 1,176 & $78 \%$ & 0.71 & 0.73 \\
\hline \multirow[t]{2}{*}{ Negative, $<0.2$} & 329 & $22 \%$ & 0.61 & 0.66 \\
\hline & & & $P=0.004$ & \\
\hline \multicolumn{5}{|l|}{ PGR mRNA status ${ }^{f}$} \\
\hline Positive, $\geq 0.1$ & 949 & $63 \%$ & 0.72 & 0.74 \\
\hline \multirow[t]{2}{*}{ Negative, $<0.1$} & 556 & $37 \%$ & 0.61 & 0.66 \\
\hline & & & $P<0.001$ & \\
\hline \multicolumn{5}{|l|}{ ESR2 mRNA status ${ }^{f}$} \\
\hline Dichotomized high, $\geq 0.005$ & 741 & $49 \%$ & 0.89 & 0.95 \\
\hline \multirow[t]{2}{*}{ Dichotomized low, $<0.005$} & 742 & $49 \%$ & 0.54 & 0.49 \\
\hline & & & $P<0.001$ & \\
\hline \multicolumn{5}{|l|}{ Invasive tumor cell content ${ }^{9}$} \\
\hline$\geq 70 \%$ & 719 & $48 \%$ & 0.57 & 0.51 \\
\hline$<70 \%$ & 786 & $52 \%$ & 0.85 & 0.91 \\
\hline & & & $P<0.001$ & \\
\hline Histological type & & & & \\
\hline $\mathrm{DCIS}+\mathrm{IDC}$ & 194 & $13 \%$ & 0.82 & 0.89 \\
\hline ILC & 135 & $9 \%$ & 0.81 & 0.94 \\
\hline IDC & 810 & $54 \%$ & 0.66 & 0.69 \\
\hline Mucinous & 40 & $3 \%$ & 0.56 & 0.65 \\
\hline Medullary & 31 & $2 \%$ & 0.69 & 1.18 \\
\hline & & & $P=0.012$ & \\
\hline Intrinsic breast cancer subtype ${ }^{h}$ & 308 & & & \\
\hline Normal-like & 22 & $7 \%$ & 1.43 & 1.19 \\
\hline ERBB2+ & 63 & $20 \%$ & 0.75 & 0.68 \\
\hline Luminal A & 76 & $25 \%$ & 0.78 & 0.89 \\
\hline
\end{tabular}


Table 1 Associations of DC-SCRIPT with clinicopathological and biological factors (Continued)

\begin{tabular}{lcccc}
\hline Luminal B & 65 & $21 \%$ & 0.56 & 0.36 \\
Basal & 82 & $27 \%$ & 0.48 & 0.48 \\
& & & $P<0.001^{e}$ & \\
\end{tabular}

${ }^{\mathrm{a}}$ Owing to missing cases, numbers do not always add up to $100 \%$. ${ }^{\mathrm{b}}$ Median level and $\mathrm{p} 50$ inter-quartile after normalization on the reference gene set. ${ }^{\mathrm{c}} \mathrm{P}$ for Spearman rank correlation test. ${ }^{d} P$ for Mann-Whitney $U$ test. ${ }^{e} P$ for Kruskal-Wallis test, including a Wilcoxon-type test for trend when appropriate. ${ }^{f}$ With quantitative polymerase chain reaction cut point for positive versus negative ESR1 and PGR, 0.2 and 0.1 , respectively, and for ESR2 at the median level of 0.005 (mRNA levels relative to reference gene set). ${ }^{9}$ Dichotomized at the median level of $70 \%$ invasive tumor cells. hIntrinsic breast cancer subtypes assigned from Affymetrix microarray by hierarchical clustering of 308 lymph-node negative disease patients who did not receive systemic adjuvant treatment. DCIS, ductal carcinoma in situ; DC-SCRIPT, dendritic cell-specific transcript gene; ERBB2+, HER2neu-positive; ESR, estrogen receptor gene; IDC, infiltrating ductal carcinoma; ILC, infiltrating lobular carcinoma; $P G R$, progesterone receptor gene; $\mathrm{pT} 1$, small tumor without lymphatic/vascular invasion.

(Spearman's rho $=0.87 ; P<0.0001)$. We therefore performed our analyses on the real-time RT-PCR data generated with the Taqman assay, which is generally considered to be more specific. Intron-spanning primer sequences for the three reference genes - that is, hydroxymethylbilane synthase (HMBS), hypoxanthine-guanine phospho-ribosyltransferase (HPRT1), and $\beta$-2-microglobulin (B2M) - and for ESR1, ESR2, PGR, and real-time PCR conditions for these SYBR-based assays were as described previously $[16,17]$. Forty rounds of amplification were performed, and fluorescent signals of the Taqman probe or SYBR green signal were used to generate cycle threshold $(\mathrm{Ct})$ values from which mRNA expression levels were calculated. Ct values of HPRT1 and $B 2 M$ were adjusted to the higher $H M B S \mathrm{Ct}$ values. Next, the expression levels of DC-SCRIPT were normalized against the average expression levels of the three reference genes as follows: mRNA target $=2^{\text {(mean Ct refer- }}$ ence genes - mean $\mathrm{Ct}$ target) [16].

\section{Tissue processing}

Primary tumor tissue was processed as described previously [16]. To assess the amount of invasive tumor cell nuclei relative to the amount of surrounding stromal cells, $5-\mu \mathrm{m}$ sections were cut for hematoxylin-andeosin staining before, during, and after the sections were cut for RNA isolation. Only specimens with at least 30\% invasive tumor cell nuclei were included in this study.

\section{Data analysis and statistics}

The relationship between DC-SCRIPT and patient and tumor characteristics was investigated with the use of non-parametric methods (Spearman rank correlations for continuous variables and Wilcoxon rank-sum for dichotomized or Kruskal-Wallis test for ordered variables). To reduce skewness, $D C$-SCRIPT levels were transformed with the Box-Cox transformation. $D C$ SCRIPT levels were dichotomized with the previously identified $66.7 \%$ high versus $33.3 \%$ low cutoff for $D C$ SCRIPT [7]. To test for an association with tumor aggressiveness and the time to progression during firstline therapy, Cox regression analysis was applied on the Box-Cox-transformed and dichotomized DC-SCRIPT
mRNA levels. The hazard ratio (HR) and its 95\% confidence interval were computed to correlate the expression levels with DFS, MFS, OS, and PFS, respectively. In multivariable analysis, Cox proportional hazards models for DFS, MFS, OS, and PFS were applied to test $D C$ $S C R I P T$ levels added to models with traditional factors. The proportional hazards assumptions were checked with Schoenfeld residuals. The analyses were stratified if necessary. The models for DFS, MFS, and OS for LNN patients who had not received adjuvant systemic therapy included age, menopausal status, tumor size, grade, and ESR1 and PGR mRNA levels. Survival curves were generated with the method of Kaplan and Meier. The log-rank test was used to test for differences between survival curves. Logistic regression was used for the association of DC-SCRIPT with clinical benefit. Computations were performed with the STATA statistical package, release 11.0 (STATA Corp., College Station, TX, USA) and SPSS 15.0 (SPSS Inc., Chicago, IL, USA). All $P$ values are two-sided, and a $P$ value of less than 0.05 was considered statistically significant.

\section{Results}

Associations of DC-SCRIPT with clinicopathological factors and histological and intrinsic breast cancer subtypes In analogy with our previous study, DC-SCRIPT mRNA expression was readily detected by quantitative RT-PCR in five normal breast tissues taken adjacent from tumor tissue and five prophylactic breast tissues (median [interquartile]: 0.063 [0.015] and 0.054 [0.035], respectively), whereas median levels were over 8 -fold lower $(P$ $<0.05)$ in 1,505 invasive breast tumors $(0.0069$ [0.0074]). Table 1 shows the median expression levels and interquartile ranges of DC-SCRIPT transcripts and relation with patient and tumor characteristics for these 1,505 patients who were evaluable for prognosis. $D C$ $S C R I P T$ levels were positively associated with tumor grade and ESR1, PGR, and ESR2 steroid hormone receptor expression level and negatively associated with invasive epithelial tumor cell content and tumor size. In addition, ESR2 was more highly expressed in tumors with a higher percentage of stromal cells (786 tumors with $30 \%$ to $70 \%$ invasive epithelial cells), and ESR1 was 
more highly expressed in tumors with a high percentage of invasive epithelial cells (719 tumors with at least 70\% invasive epithelial cells) $(P<0.001)$ (data not shown). High levels of DC-SCRIPT were found in breast tumors with a ductal carcinoma in situ (DCIS) component or infiltrating lobular carcinoma compared with infiltrating ductal carcinomas (both $P<0.01$ ). Of 308 LNN tumors, intrinsic subtyping data were available [20]. In these tumors, basal-like tumors had the lowest levels and normal-like breast tumors expressed significantly higher levels of DC-SCRIPT compared with the other intrinsic subtypes $(P<0.001$; Figure S1 in Additional file 2$)$. Furthermore, luminal A tumors expressed higher levels of DC-SCRIPT and ESR2 but lower levels of ESR1 compared with luminal $B$ tumors (median levels in luminal A versus luminal B: 0.0078 and 0.056 for DC-SCRIPT [P $=0.003], 0.0095$ and 0.0023 for ESR2 [ $P<0.001]$, and 6.1 and 13.6 for $\operatorname{ESR} 1[P<0.001])$. This may be explained at least partly by the fact that, in this cohort of $308 \mathrm{LNN}$ tumors, the luminal B tumors contained a higher percentage of invasive epithelial cells (mean \pm standard deviation [SD]: $77 \% \pm 9 \%$ for the $n=64$ luminal B tumors versus $67 \% \pm 12 \%$ for the $n=71$ luminal A tumors).

\section{DC-SCRIPT and tumor aggressiveness in univariate and multivariable analyses}

In the analyses including all 1,505 M0 patients, increasing levels of DC-SCRIPT mRNA were significantly associated with favorable DFS, MFS, and OS (HR 0.78, 0.74, and 0.77, respectively; all $P<0.001$ ). To test for a relation between DC-SCRIPT mRNA levels and tumor aggressiveness (that is, the natural course of the disease without the confounding effect of systemic adjuvant therapy), we restricted our next analyses of MFS to those 837 LNN disease patients who had not received (neo)adjuvant systemic therapy. The significant relationships of DC-SCRIPT as a continuous variable in these univariate analyses justified the use of the previously identified cut point that dichotomized the cohort in $33.3 \%$ of the patients with low levels and $66.7 \%$ of patients with high levels of DC-SCRIPT mRNA in their primary tumors [7]. In univariate analysis, high levels of $D C$-SCRIPT were significantly associated with a favorable prognosis (HR $0.55 ; P<0.001$ ) (Table 2). When added to a multivariable base model for LNN disease - which included the traditional prognostic factors of age, menopausal status, grade, and $P G R$ - stratified by ESR1 and tumor size to meet the proportional hazards assumption, the association of $D C-S C R I P T$ with MFS remained highly significant (HR $0.60 ; P<0.001$ ) (Table 2). Adding ESR2 to the model did not significantly affect the prognostic value of $D C$-SCRIPT in these analyses (Table 2).

Because the proportional hazards assumptions were violated by ESR1 and tumor size and because DC-
SCRIPT is a transcriptional co-regulator of nuclear receptors - including the, for breast cancer biologically relevant, steroid hormone receptors - we next explored its prognostic value as continuous variable in subgroups of tumors stratified by steroid hormone receptor status and tumor size (Table 3 and Figure 1). Subdividing the 837 primary LNN tumors into ESR1-positive and -negative [14] showed that increasing levels of $D C$ $S C R I P T$ were, in univariate and multivariable analyses, associated with good prognosis only for the patients with ESR1-positive tumors. Subdividing these LNN tumors at the median level of ESR2 into high and low revealed that, in contrast to ESR1, increasing levels of $D C$-SCRIPT were, in both univariate and multivariable analyses, associated with good prognosis only for patients with primary tumors with low levels of ESR2. With respect to tumor size, in univariate and multivariable analyses, increasing levels of DC-SCRIPT were associated with good prognosis only for pT1 (small tumor without lymphatic/vascular invasion) tumors and not for larger tumors. These and additional exploratory Cox univariate analyses are summarized in Table 3 . The prognostic value of DC-SCRIPT is visualized in KaplanMeier curves (Figure 1) as a dichotomized variable in these biologically relevant LNN ESR1-negative (Figure 1a) and -positive (Figure 1b) and LNN ESR2-high (Figure 1d) and -low (Figure 1e) subsets in combination with patients with pT1 primary tumors (Figure 1c, f).

\section{$D C$-SCRIPT and response to first-line endocrine therapy}

DC-SCRIPT expression levels were evaluated in 296 hormone-naïve ER-positive primary breast tumors from patients whose relapse was treated with first-line tamoxifen monotherapy. These patients had not received (neo) adjuvant endocrine systemic treatment. In univariate analyses, no statistically significant associations were observed between DC-SCRIPT as transformed continuous variable and PFS or clinical benefit after start of first-line treatment with tamoxifen $(\mathrm{HR}=1.08[0.99$ to 1.18], $P=0.07$ and odds ratio $=0.88$ [0.74 to 1.05 ], $P=$ 0.16 , respectively).

\section{Discussion}

DC-SCRIPT has been identified as a key modulator of nuclear receptor activity that has prognostic value in breast cancer [7]. The clinical conclusions about DC-SCRIPT mRNA expression as a prognostic marker in breast cancer were based on non-randomized retrospective analyses in three small, breast cancer cohorts from Nijmegen (The Netherlands) and still required independent validation. In this study, we provide a higher level of evidence as we confirm that mRNA expression values of DC-SCRIPT indicate outcome in an independent retrospective cohort of 1,505 primary 
Table 2 Univariate and multivariable analyses for metastasis-free survival as a function of DC-SCRIPT in lymph nodenegative disease

\begin{tabular}{|c|c|c|c|c|c|c|c|c|c|}
\hline \multirow[b]{2}{*}{ Factor } & \multirow[b]{2}{*}{ Number } & \multicolumn{4}{|c|}{ Univariate analysis } & \multicolumn{4}{|c|}{ Multivariate analysis $^{a}$} \\
\hline & & HR & $95 \%$ & $\circ \mathrm{Cl}$ & $P$ value & HR & & & $P$ value \\
\hline \multicolumn{10}{|l|}{ Age, years } \\
\hline$\leq 40$ & 114 & 1 & & & & 1 & & & \\
\hline $41-55$ & 295 & 0.88 & 0.63 & 1.22 & & 0.95 & 0.67 & 1.35 & \\
\hline $56-70$ & 270 & 0.72 & 0.51 & 1.02 & & 0.69 & 0.40 & 1.20 & \\
\hline$>70$ & 158 & 0.53 & 0.35 & 0.81 & $<0.01$ & 0.49 & 0.27 & 0.90 & 0.077 \\
\hline \multicolumn{10}{|l|}{ Menopausal status } \\
\hline Premenopausal & 350 & 1 & & & & 1 & & & \\
\hline Postmenopausal & 487 & 0.78 & 0.62 & 0.97 & 0.028 & 1.08 & 0.70 & 1.66 & 0.731 \\
\hline \multicolumn{10}{|l|}{ Grade } \\
\hline Poor & 422 & 1 & & & & 1 & & & \\
\hline Unknown & 262 & 1.02 & 0.79 & 1.30 & & 1.12 & 0.87 & 1.44 & \\
\hline Moderate and good & 153 & 0.49 & 0.34 & 0.71 & $<0.001$ & 0.54 & 0.37 & 0.78 & $<0.001$ \\
\hline \multicolumn{10}{|l|}{$P G R$ mRNA status ${ }^{b}$} \\
\hline Negative, $<0.1$ & 312 & 1 & & & & 1 & & & \\
\hline Positive, $\geq 0.1$ & 525 & 0.68 & 0.54 & 0.85 & 0.001 & 0.71 & 0.53 & 0.95 & 0.022 \\
\hline
\end{tabular}

Tumor size

$\leq 2 \mathrm{~cm}$
$>2 \mathrm{~cm}+$ unknown

ESR1 mRNA status ${ }^{\mathrm{b}}$

Negative, $<0.2$

Positive, $\geq 0.2$

Factor analyzed

DC-SCRIPT

Continuous

$33.3 \%$ low

$66.7 \%$ high

ESR2 mRNA status ${ }^{\mathrm{b}}$

Continuous

Dichotomized low, $<0.005$

Dichotomized high, $\geq 0.005$

DC-SCRIPT and ESR2 combined

\section{Both low}

DC-SCRIPT low, ESR2 high

DC-SCRIPT high, ESR2 low

Both high

\section{$378 \quad 1$}

$\begin{array}{lllll}459 & 1.26 & 1.00 & 1.59 & 0.047\end{array}$

$$
\begin{array}{ccccc}
199 & 1 & & & \\
638 & 0.77 & 0.59 & 0.99 & 0.040
\end{array}
$$

$837 \quad 0.77 \quad 0.67 \quad 0.88 \quad<0.001$$$
277 \quad 1
$$$$
\begin{array}{llllll}
560 & 0.55 & 0.43 & 0.69<0.001 & 0.60
\end{array}
$$$$
\begin{array}{llllll}
820 & 0.88 & 0.79 & 0.99 & 0.034 & 0.86
\end{array}
$$$$
410 \quad 1
$$$$
\begin{array}{lllll}
410 & 0.80 & 0.63 & 1.00 & 0.052
\end{array}
$$

0.80
1
0.60
0.86
1.00
0.75

$$
183 \quad 1
$$

$$
\begin{array}{llll}
91 & 0.74 & 0.51 & 1.08
\end{array}
$$$$
\begin{array}{llll}
227 & 0.49 & 0.36 & 0.67
\end{array}
$$$$
319 \quad 0.50 \quad 0.38 \quad 0.67<0.001
$$

Additions to the base model

$\begin{array}{lll}0.70 & 0.92 & 0.001 \\ 0.47 & 0.76 & <0.001 \\ 0.76 & 0.96 & 0.011 \\ 0.59 & 0.94 & 0.014\end{array}$

1.04

0.76

0.69

$\begin{array}{lll}0.71 & 0.49 & 1.04 \\ 0.55 & 0.40 & 0.76 \\ 0.52 & 0.39 & 0.69\end{array}$

$<0.001$

a Multivariable analyses were conducted in two blocks. First, a model including all established clinicopathological factors was fitted. The Cox proportional hazards assumptions were checked and the analyses were stratified by tumor size and ESR1 to meet the proportional hazards assumption. In a second block, the contributions of DC-SCRIPT and ESR2 (as continuous or dichotomized variables) were investigated. ${ }^{b}$ With quantitative polymerase chain reaction cut point for positive versus negative ESR1 and PGR, 0.2 and 0.1 , respectively, and for ESR2 at the median level of 0.005 (mRNA levels relative to reference gene set). Cl, confidence interval; DC-SCRIPT, dendritic cell-specific transcript gene; ESR, estrogen receptor gene; HR, hazard ratio; PGR, progesterone receptor gene; pT1, small tumor without lymphatic/vascular invasion.

breast cancers from Rotterdam. In addition, we confirm that DC-SCRIPT mRNA expression is a pure prognostic marker as it indicates - independently of current clinical prognostic markers such as age, menopausal status, grade, tumor size, and receptor status - the occurrence of distant metastasis in patients who did not receive any adjuvant systemic treatment. Because we used mRNA extracted from tumor tissue and a different mRNA isolation method (RNA-B versus column-based), an independent real-time PCR assay to detect DC-SCRIPT, a different type of machine to amplify the transcript, and personnel from another institute, we consider $D C$ $S C R I P T$ a robust prognostic marker for patients with early breast cancer. The patients described in this 
Table 3 Disease-free survival, metastasis-free survival, and overall survival as a function of continuous DC-SCRIPT in lymph node-negative disease

\begin{tabular}{|c|c|c|c|c|c|c|c|c|c|c|c|c|c|}
\hline \multirow{3}{*}{$\begin{array}{l}\text { Association with continuous DC-SCRIPT } \\
\text { Cohort } \\
\text { Lymph node-negative }\end{array}$} & \multirow{3}{*}{$\begin{array}{c}\text { Number } \\
837\end{array}$} & \multicolumn{4}{|c|}{ Disease-free survival } & \multicolumn{4}{|c|}{ Metastasis-free survival } & \multicolumn{4}{|c|}{ Overall survival } \\
\hline & & \multirow{2}{*}{$\begin{array}{l}\text { HR } \\
0.82\end{array}$} & \multicolumn{2}{|c|}{$95 \% \mathrm{Cl}$} & \multirow{2}{*}{$\begin{array}{c}P \text { value } \\
0.001\end{array}$} & \multirow{2}{*}{$\begin{array}{l}\text { HR } \\
0.77\end{array}$} & \multicolumn{2}{|c|}{$95 \% \mathrm{Cl}$} & \multirow{2}{*}{$\begin{array}{l}\boldsymbol{P} \text { value } \\
<0.001\end{array}$} & \multirow{2}{*}{$\begin{array}{l}\text { HR } \\
0.82\end{array}$} & \multicolumn{2}{|c|}{$95 \% \mathrm{Cl}$} & \multirow{2}{*}{$\frac{P \text { value }}{0.005}$} \\
\hline & & & 0.73 & 0.93 & & & 0.67 & 0.88 & & & 0.72 & 0.94 & \\
\hline ESR1 mRNA-negative ${ }^{a}$ & 199 & 0.94 & 0.76 & 1.17 & 0.59 & 0.93 & 0.73 & 1.18 & 0.53 & 0.88 & 0.70 & 1.11 & 0.30 \\
\hline ESR1 mRNA-positive ${ }^{a}$ & 638 & 0.79 & 0.68 & 0.90 & 0.001 & 0.72 & 0.62 & 0.85 & $<0.001$ & 0.81 & 0.69 & 0.96 & 0.014 \\
\hline$P G R$ mRNA-negative ${ }^{a}$ & 312 & 0.88 & 0.74 & 1.06 & 0.19 & 0.84 & 0.69 & 1.03 & 0.10 & 0.88 & 0.72 & 1.08 & 0.22 \\
\hline$P G R$ mRNA-positive ${ }^{a}$ & 525 & 0.81 & 0.69 & 0.94 & 0.007 & 0.75 & 0.63 & 0.89 & 0.001 & 0.82 & 0.68 & 0.99 & 0.04 \\
\hline ESR2 mRNA-low ${ }^{\text {a }}$ & 410 & 0.76 & 0.64 & 0.91 & 0.003 & 0.69 & 0.56 & 0.84 & $<0.001$ & 0.73 & 0.64 & 0.97 & 0.026 \\
\hline ESR2 mRNA-high ${ }^{a}$ & 410 & 0.93 & 0.78 & 1.11 & 0.43 & 0.89 & 0.73 & 1.09 & 0.26 & 0.92 & 0.75 & 1.13 & 0.41 \\
\hline Tumor size $\leq 2 \mathrm{~cm}(\mathrm{pT} 1)^{\mathrm{b}}$ & 378 & 0.74 & 0.61 & 0.89 & 0.001 & 0.67 & 0.54 & 0.83 & 0.000 & 0.73 & 0.59 & 0.91 & 0.005 \\
\hline Tumor size $>2 \mathrm{~cm}^{\mathrm{b}}$ & 459 & 0.92 & 0.79 & 1.08 & 0.31 & 0.86 & 0.72 & 1.03 & 0.10 & 0.91 & 0.76 & 1.09 & 0.31 \\
\hline ESR1 mRNA-positive, tumor size $\leq 2 \mathrm{~cm}$ & 306 & 0.69 & 0.56 & 0.85 & 0.001 & 0.61 & 0.48 & 0.78 & $<0.001$ & 0.72 & 0.56 & 0.93 & 0.010 \\
\hline ESR1 mRNA-positive, tumor size $>2 \mathrm{~cm}$ & 332 & 0.91 & 0.75 & 1.10 & 0.34 & 0.84 & 0.68 & 1.05 & 0.13 & 0.90 & 0.72 & 1.14 & 0.39 \\
\hline ESR2 mRNA-low, tumor size $\leq 2 \mathrm{~cm}$ & 175 & 0.57 & 0.43 & 0.76 & $<0.001$ & 0.51 & 0.37 & 0.70 & $<0.001$ & 0.60 & 0.44 & 0.83 & 0.002 \\
\hline ESR2 mRNA-high, tumor size $>2 \mathrm{~cm}$ & 218 & 0.98 & 0.78 & 1.23 & 0.84 & 0.91 & 0.71 & 1.18 & 0.49 & 0.93 & 0.74 & 1.21 & 0.58 \\
\hline ESR1-positive and ESR2-low, tumor size $\leq 2 \mathrm{~cm}$ & 147 & 0.63 & 0.45 & 0.87 & 0.005 & 0.54 & 0.38 & 0.78 & $<0.001$ & 0.63 & 0.43 & 0.92 & 0.017 \\
\hline ESR1-positive and ESR2-low, tumor size $>2 \mathrm{~cm}$ & 181 & 0.94 & 0.71 & 1.24 & 0.66 & 0.94 & 0.68 & 1.29 & 0.69 & 1.03 & 0.73 & 1.45 & 0.89 \\
\hline ESR1-positive or ESR2-low or both, tumor size $\leq 2 \mathrm{~cm}$ & 334 & 0.65 & 0.53 & 0.79 & $<0.001$ & 0.57 & 0.46 & 0.71 & $<0.001$ & 0.67 & 0.53 & 0.84 & 0.001 \\
\hline ESR1-positive or ESR2-low or both, tumor size $>2 \mathrm{~cm}$ & 386 & 0.90 & 0.76 & 1.08 & 0.25 & 0.81 & 0.66 & 0.99 & 0.037 & 0.87 & 0.71 & 1.07 & 0.20 \\
\hline
\end{tabular}

With quantitative polymerase chain reaction cut point for positive versus negative ESR1 and $P G R, 0.2$ and 0.1 , respectively, and for ESR2 at the median level of 0.005 (mRNA levels relative to reference gene set). ${ }^{\mathrm{b}}$ Interaction with continuous DC-SCRIPT $(P<0.05)$. Cl, confidence interval; $D C$-SCRIPT, dendritic cell-specific transcript gene; ESR, estrogen receptor gene; HR, hazard ratio; $P G R$, progesterone receptor gene; $\mathrm{pT1}$, small tumor without lymphatic/vascular invasion.

retrospective study entered the clinic during 1978 to 2000. During this period, adjuvant therapy was not as widespread as it is nowadays; this circumstance was at the same time the strength of our cohort for the evaluation of a prognostic marker. The data that emerged from this study thus validate the hypothesis that $D C$ SCRIPT is associated with good prognosis in early disease and support the idea that DC-SCRIPT acts as a tumor suppressor in breast cancer progression [7].

Because of the size of this cohort and the biological function of DC-SCRIPT as a nuclear receptor co-regulator, we were able to include additional subgroup analyses to extend our insights into the clinical behavior and relevance of measuring $D C-S C R I P T$ in primary breast cancers. High levels of DC-SCRIPT mRNA in primary tumors of breast cancer patients were significantly related with tumor characteristics that are associated with good prognosis, such as DCIS, infiltrating lobular carcinoma, breast tumors of the normal-like and luminal A subtype, and small (pT1), well-differentiated, steroid hormone receptor-positive tumors. While ESR1 is localized mainly in tumors with at least $70 \%$ invasive epithelial cells $(P<0.001)$, we showed for both ESR2 and $D C$-SCRIPT a positive correlation with tumors with less than $70 \%$ invasive epithelial cells $(P<0.001)$. As normal epithelial cells in tumors with less than $70 \%$ invasive epithelial cells express the highest levels of DC-SCRIPT, they could be responsible for this correlation. Furthermore, infiltrating leukocytes in the stroma might have contributed to the detected signal [4,5]. Alternatively, or additionally, stromal cells may have played a role in the induction of DC-SCRIPT in the epithelial tumor cells. In analogy, ESR2 is - apart from breast cancer epithelial tumor cells - also expressed in adjacent infiltrating lymphocytes, fibroblasts, and endothelial cells [3].

Interestingly, in tumors that express relatively high ESR2 mRNA levels and that in general have a higher stromal content, DC-SCRIPT expression has little or no prognostic value. Thus, while in early ESR1-positive breast cancer DC-SCRIPT inhibits progression of breast cancer, this effect appears to be neutralized in tumors high in ESR2. Indeed, ESR2 has been reported to be dominant over ESR1 and able to counteract the proliferation-inducing activities of ESR1 [1,2]. Unraveling the precise role of DC-SCRIPT in the complex genomic and non-genomic interplay between ESR1, ESR2, and their isoforms [21-23] might turn out to be rewarding for elucidating the 'yin-yang' role of these factors in breast cancer.

As DC-SCRIPT can inhibit ER $\alpha$ and PR activity, a second aim of the study was to address whether DCSCRIPT affects the response to endocrine therapy. In our previous study, we had already explored the value of DC-SCRIPT mRNA expression to indicate outcome in a cohort of breast cancer patients who received adjuvant tamoxifen [7]. However, in the adjuvant setting - that, for ethical reasons, nowadays includes only non-randomly assigned patients among treated and untreated 
(a) ESR1 negative primary breast tumors

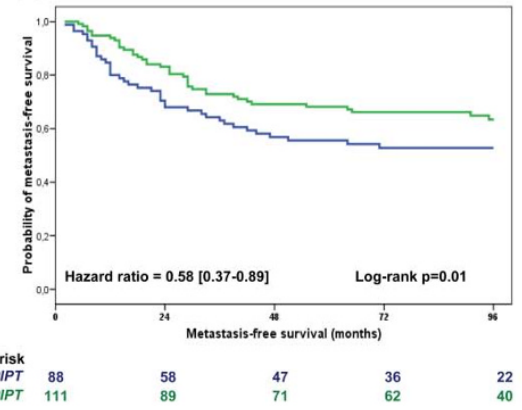

(b) ESR1 positive primary breast tumors

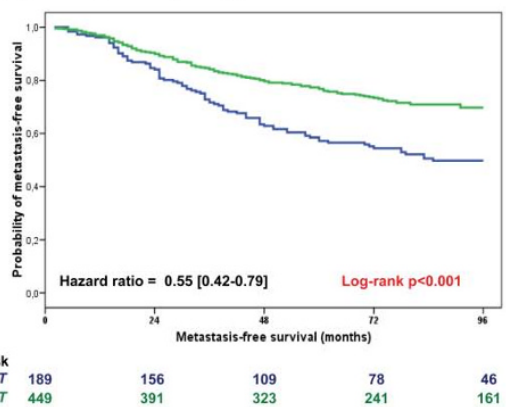

(c) ESR1 positive $\mathrm{pT} 1$ primary breast tumors

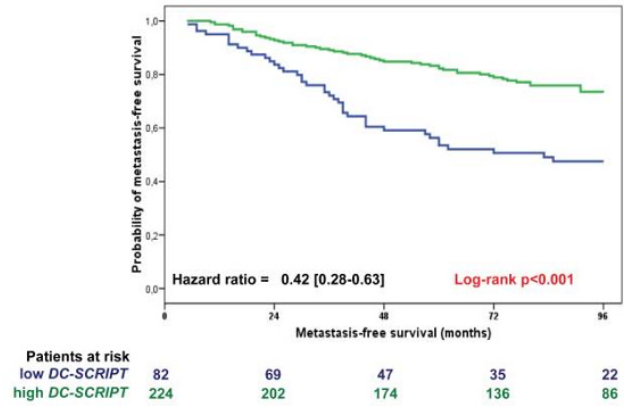

(d) ESR2 low primary breast tumors

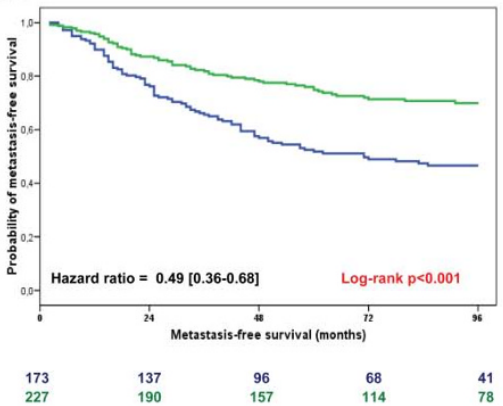

(e) ESR2 high primary breast tumors

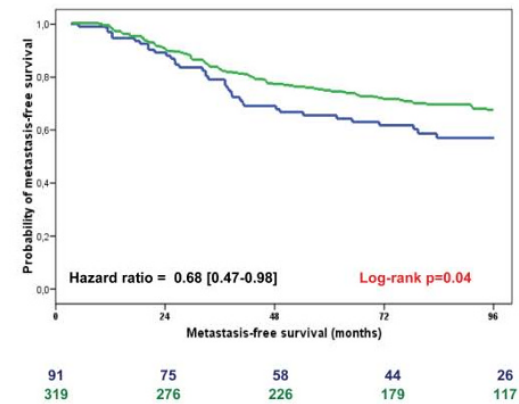

(f) ESR2 low pT1 primary breast tumors

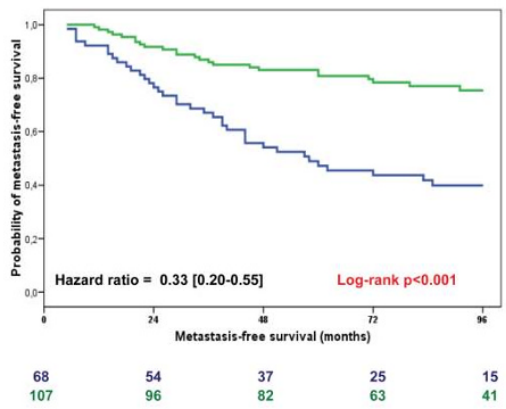

Figure 1 Metastasis-free survival as a function of dichotomized DC-SCRIPT. Metastasis-free survival is shown as a function of dichotomized DC-SCRIPT in 837 lymph-node negative, primary breast cancer patients after subdividing them according high and low ESR1 and ESR2 in the primary tumor and tumor size. (a) ESR1 negative primary breast tumors, (b) ESR1 positive primary breast tumors, (c) ESR1 positive pT1 primary breast tumors, (d) ESR2 low primary breast tumors, (e) ESR2 high primary breast tumors, (f) ESR2 low pT1 primary breast tumors. Quantitative polymerase chain reaction cut points are shown for high versus low DC-SCRIPT (66.7\% versus 33.3\%) [7], for positive versus negative ESR1 (0.2) [14], and for ESR2-low versus -high at the median level of 0.005 (mRNA levels relative to reference gene set). Patients at risk are indicated. DCSCRIPT, dendritic cell-specific transcript; ESR, estrogen receptor; pT1, small tumor without lymphatic/vascular invasion.

arms - one cannot discriminate between tumor aggressiveness and response to treatment [24]. The current retrospective study included hormone-naïve patients (that is, not having received any [neo]adjuvant endocrine treatment) who received first-line tamoxifen treatment for their advanced disease and therefore was better suited to study a putative relation of DC-SCRIPT and response to therapy. Despite the positive association of DC-SCRIPT with ESR1, DC-SCRIPT levels were unable to identify patients with ESR1-positive primary tumors at high or low risk to progress if treated with tamoxifen. Thus, although DC-SCRIPT can modulate the activity of $E S R 1$, it does not affect the response to endocrine therapy with tamoxifen in advanced breast cancer. The early loss of DC-SCRIPT during cancer progression might explain this absence of a response in the metastatic disease setting.

\section{Conclusions}

This independent retrospective quantitative RT-PCR study validates that high levels of DC-SCRIPT are associated with reduced tumor aggressiveness. The association is particularly strong for small tumors with high ESR1 or low ESR2 mRNA levels or both. Finally, although DC-SCRIPT negatively regulates ESR1 and $P G R$ activity, DC-SCRIPT levels measured in the 
primary tumors are not associated with response to first-line endocrine treatment for advanced disease. This finding is in line with DC-SCRIPT as an early marker for disease.

\section{Additional material}

Additional file 1: Supplementary materials and methods. A word file containing additional Materials and methods [25-28].

Additional file 2: Figure S1 - DC-SCRIPT mRNA expression in breast cancer subtypes. The box-plot shows the five statistics (lower whisker is $5 \%$ minimum, lower box part is $25^{\text {th }}$ percentile, solid line in box presents the median, upper box part is $75^{\text {th }}$ percentile and upper whisker is $95 \%$ maximum). Figure depicts $P$ for Mann-Whitney $U$ test to identify significantly different expression of DC-SCRIPT in between subtypes.

\section{Abbreviations}

B2M: beta-2-microglobulin gene; bp: base product; Ct: cycle threshold; DCIS: ductal carcinoma in situ; DC-SCRIPT: dendritic cell-specific transcript; DFS: disease-free survival; ER: estrogen receptor; ESR: estrogen receptor gene; HMBS: hydroxymethylbilane synthase gene; HPRT1: hypoxanthine guanine phosphoribosyltransferase 1 gene; HR: hazard ratio; LNN: lymph nodenegative; M0: no metastasis; M1: with metastasis; MFS: metastasis-free survival; OS: overall survival; PCR: polymerase chain reaction; PFS: progression-free survival; PGR: progesterone receptor gene; PPAR: peroxisome proliferator-activated receptor; pT1: small tumor without lymphatic/vascular invasion; PR: progesterone receptor; RAR: retinoic acid receptor; RT-PCR: reverse transcriptase polymerase chain reaction; SYBR: N',N'dimethyl-N-[4-[(E)-(3-methyl-1,3-benzothiazol-2-ylidene)methyl]-1phenylquinolin-1-ium-2-yl]-N-propylpropane-1,3-diamine.

\section{Acknowledgements}

We especially thank the patients and surgeons, pathologists, and internists for their assistance in collecting tumor tissues and patients' clinical follow-up data. We thank Joan Bolt, Marion Meijer, Mieke Timmermans, Anita Trapman, and Wendy van der Smissen for their excellent technical support. This work was financially supported by $\mathrm{VICl}$ grant 918-66-615 (awarded to GJA) from the Netherlands Organization for Scientific Research (NWO).

\section{Author details}

'Department of Medical Oncology, Josephine Nefkens Institute and Cancer Genomics Centre, Erasmus Medical Center, Dr. Molewaterplein 50, Rotterdam, 3015 GE, The Netherlands. ${ }^{2}$ Department of Tumor Immunology, Nijmegen Centre for Molecular Life Sciences, Radboud University Nijmegen Medical Centre, Geert Grooteplein 28, Nijmegen, 6525 GA, The Netherlands. ${ }^{3}$ Department of Radiation Oncology and Department of Laboratory Medicine, Radboud University Nijmegen Medical Centre, Geert Grooteplein 32, Nijmegen, 6525 GA, The Netherlands.

\section{Authors' contributions}

AMS participated in the study design, collected laboratory data on the patients, performed laboratory work and statistical analyses, and wrote the manuscript. MA participated in the study design, performed laboratory work, and provided critical revision of the manuscript. MPL collected laboratory data on the patients, performed the clinical statistical analyses, and provided critical revision of the manuscript. PNS provided critical revision of the manuscript and participated in the study design. VdW and AvG performed the laboratory work and provided critical revision of the manuscript. JAF and JWMM participated in the study design, provided the study material and clinical information, and provided critical revision of the manuscript. GJA participated in the study design and provided critical revision of the manuscript. All authors read and approved the final manuscript.

\section{Competing interests}

The authors declare that they have no competing interests.
Received: 31 August 2010 Revised: 12 November 2010

Accepted: 1 December 2010 Published: 1 December 2010

\section{References}

1. Strom A, Hartman J, Foster JS, Kietz S, Wimalasena J, Gustafsson JA: Estrogen receptor beta inhibits 17 beta-estradiol-stimulated proliferation of the breast cancer cell line T47D. Proc Natl Acad Sci USA 2004 101:1566-1571.

2. Liu MM, Albanese C, Anderson CM, Hilty K, Webb P, Uht RM, Price RH Jr, Pestell RG, Kushner PJ: Opposing action of estrogen receptors alpha and beta on cyclin D1 gene expression. J Biol Chem 2002, 277:24353-24360.

3. Hartman J, Strom A, Gustafsson JA: Estrogen receptor beta in breast cancer-diagnostic and therapeutic implications. Steroids 2009, 74:635-641.

4. Triantis V, Moulin V, Looman MW, Hartgers FC, Janssen RA, Adema GJ: Molecular characterization of the murine homologue of the DC-derived protein DC-SCRIPT. J Leukoc Biol 2006, 79:1083-1091.

5. Triantis $V$, Trancikova DE, Looman MW, Hartgers FC, Janssen RA, Adema GJ: Identification and characterization of DC-SCRIPT, a novel dendritic cellexpressed member of the zinc finger family of transcriptional regulators. J Immunol 2006, 176:1081-1089.

6. Lopez-Garcia J, Periyasamy M, Thomas RS, Christian M, Leao M, Jat $P$, Kindle KB, Heery DM, Parker MG, Buluwela L, Kamalati T, Ali S: ZNF366 is an estrogen receptor corepressor that acts through CtBP and histone deacetylases. Nucleic Acids Res 2006, 34:6126-6136.

7. Ansems M, Hontelez S, Looman MW, Karthaus N, Bult P, Bonenkamp JJ, Jansen JH, Sweep FC, Span PN, Adema GJ: DC-SCRIPT: nuclear receptor modulation and prognostic significance in primary breast cancer. J Natl Cancer Inst 2010, 102:54-68.

8. Ramadoss P, Marcus C, Perdew GH: Role of the aryl hydrocarbon receptor in drug metabolism. Expert Opin Drug Metab Toxicol 2005, 1:9-21.

9. Osborne CK, Schiff R, Fuqua SA, Shou J: Estrogen receptor: current understanding of its activation and modulation. Clin Cancer Res 2001, 7:4338s-4342s, discussion $4411 \mathrm{~s}-4412 \mathrm{~s}$

10. Code of Conduct of the Federation of Medical Scientific Societies in the Netherlands. [http://www.federa.org/?s=1\&m=99].

11. McShane LM, Altman DG, Sauerbrei W, Taube SE, Gion M, Clark GM: REporting recommendations for tumor MARKer prognostic studies (REMARK). Breast Cancer Res Treat 2006, 100:229-235.

12. Jansen MP, Sieuwerts AM, Look MP, Ritstier K, Meijer-van Gelder ME, van Staveren IL, Klijn JG, Foekens JA, Berns EM: HOXB13-to-IL17BR expression ratio is related with tumor aggressiveness and response to tamoxifen of recurrent breast cancer: a retrospective study. J Clin Oncol 2007, 25:662-668.

13. Sieuwerts AM, Look MP, Meijer-van Gelder ME, Timmermans M, Trapman AM, Garcia RR, Arnold M, Goedheer AJ, de Weerd V, Portengen H, Klijn JG, Foekens JA: Which cyclin E prevails as prognostic marker for breast cancer? Results from a retrospective study involving 635 lymph node-negative breast cancer patients. Clin Cancer Res 2006, 12:3319-3328.

14. Sieuwerts AM, Usher PA, Meijer-van Gelder ME, Timmermans M, Martens JW, Brunner N, Klijn JG, Offenberg H, Foekens JA: Concentrations of TIMP1 mRNA splice variants and TIMP-1 protein are differentially associated with prognosis in primary breast cancer. Clin Chem 2007, 53:1280-1288

15. Foekens JA, Portengen $H$, van Putten $W L$, Peters $H A$, Krijnen $H L$, AlexievaFigusch J, Klijn JG: Prognostic value of estrogen and progesterone receptors measured by enzyme immunoassays in human breast tumor cytosols. Cancer Res 1989, 49:5823-5828.

16. Sieuwerts AM, Meijer-van Gelder ME, Timmermans M, Trapman AM, Garcia RR, Arnold M, Goedheer AJ, Portengen H, Klijn JG, Foekens JA: How ADAM-9 and ADAM-11 differentially from estrogen receptor predict response to tamoxifen treatment in patients with recurrent breast cancer: a retrospective study. Clin Cancer Res 2005, 11:7311-7321.

17. Dorssers LC, van Agthoven T, Brinkman A, Veldscholte J, Smid M, Dechering KJ: Breast cancer oestrogen independence mediated by BCAR1 or BCAR3 genes is transmitted through mechanisms distinct from the oestrogen receptor signalling pathway or the epidermal growth factor receptor signalling pathway. Breast Cancer Res 2005, 7: R82-92.

18. Hayward JL, Carbone PP, Heuson JC, Kumaoka S, Segaloff A, Rubens RD: Assessment of response to therapy in advanced breast cancer: a project 
of the Programme on Clinical Oncology of the International Union Against Cancer, Geneva, Switzerland. Cancer 1977, 39:1289-1294.

19. Foekens JA, Peters HA, Grebenchtchikov N, Look MP, Meijer-van Gelder ME, Geurts-Moespot A, van der Kwast TH, Sweep CG, Klijn JG: High tumor levels of vascular endothelial growth factor predict poor response to systemic therapy in advanced breast cancer. Cancer Res 2001, 61:5407-5414.

20. Smid M, Wang Y, Zhang Y, Sieuwerts AM, Yu J, Klijn JG, Foekens JA, Martens JW: Subtypes of breast cancer show preferential site of relapse. Cancer Res 2008, 68:3108-3114.

21. Lee LM, Cao J, Deng H, Chen P, Gatalica Z, Wang ZY: ER-alpha36, a novel variant of ER-alpha, is expressed in ER-positive and -negative human breast carcinomas. Anticancer Res 2008, 28:479-483.

22. Chen JQ, Russo PA, Cooke C, Russo IH, Russo J: ERbeta shifts from mitochondria to nucleus during estrogen-induced neoplastic transformation of human breast epithelial cells and is involved in estrogen-induced synthesis of mitochondrial respiratory chain proteins. Biochim Biophys Acta 2007, 1773:1732-1746.

23. Shaaban AM, Green AR, Karthik S, Alizadeh Y, Hughes TA, Harkins L, Ellis IO, Robertson JF, Paish EC, Saunders PT, Groome NP, Speirs V: Nuclear and cytoplasmic expression of ERbeta1, ERbeta2, and ERbeta5 identifies distinct prognostic outcome for breast cancer patients. Clin Cancer Res 2008, 14:5228-5235.

24. Jansen MP, Foekens JA, Klijn JG, Berns EM: Re: Limits of predictive models using microarray data for breast cancer clinical treatment outcome. $J$ Natl Cancer Inst 2005, 97:1851-1852, author reply 1852-1853.

25. Foekens JA, Look MP, Bolt-de Vries J, Meijer-van Gelder ME, van Putten WL, Klijn JG: Cathepsin-D in primary breast cancer: prognostic evaluation involving 2810 patients. Br J Cancer 1999, 79:300-307.

26. van Agthoven T, Sieuwerts AM, Meijer-van Gelder ME, Look MP, Smid M, Veldscholte J, Sleijfer S, Foekens JA, Dorssers LC: Relevance of breast cancer antiestrogen resistance genes in human breast cancer progression and tamoxifen resistance. J Clin Oncol 2009, 27:542-549.

27. Meijer-van Gelder ME, Look MP, Peters HA, Schmitt M, Brunner N, Harbeck N, Klijn JG, Foekens JA: Urokinase-type plasminogen activator system in breast cancer: association with tamoxifen therapy in recurrent disease. Cancer Res 2004, 64:4563-4568.

28. Martens JW, Nimmrich I, Koenig T, Look MP, Harbeck N, Model F, Kluth A, Bolt-de Vries J, Sieuwerts AM, Portengen H, Meijer-Van Gelder ME, Piepenbrock C, Olek A, Höfler H, Kiechle M, Klijn JG, Schmitt M, Maier S, Foekens JA: Association of DNA methylation of phosphoserine aminotransferase with response to endocrine therapy in patients with recurrent breast cancer. Cancer Res 2005, 65:4101-4117.

\section{doi:10.1186/bcr2786}

Cite this article as: Sieuwerts et al:: Clinical significance of the nuclear receptor co-regulator DC-SCRIPT in breast cancer: an independent retrospective validation study. Breast Cancer Research 2010 12:R103.

\section{Submit your next manuscript to BioMed Central and take full advantage of:}

- Convenient online submission

- Thorough peer review

- No space constraints or color figure charges

- Immediate publication on acceptance

- Inclusion in PubMed, CAS, Scopus and Google Scholar

- Research which is freely available for redistribution 